\title{
长江下游近代洪水事件重建的新证据
}

\author{
展望 ${ }^{(1)}$, 杨守业 ${ }^{(1 *}$, 刘晓理 ${ }^{(1)}$, 李健伟 ${ }^{(1)}$, Choi Man-Sik ${ }^{(2)}$ \\ (1) 同济大学海洋地质国家重点实验室, 上海 200092; \\ (2) Division of Earth and Environmental Sciences, Chungnam National University, Daejeon, 305-764, Korea \\ * 联系人, E-mail: syyang@ tongji.edu.cn
}

2009-11-06 收稿, 2010-04-07 接受

国家自然科学基金资助项目(40676031, 40830107)

\begin{abstract}
摘要 全新世古洪水事件的重建是当前全球变化研究的一个热点. 通过长江下游一个稳定江心洲 上沉积剖面的粒度和有机元素组成分析, 清晰地揭示出主要粒度参数、概率累积曲线和 $C-M$ 图可 以指示洪水事件沉积, 而沉积有机质的 TOC/TN 因为反映大洪水期间, 长江流域强烈的地表冲刷将 大量降解不完全的碎屑有机质带入下游, 也成为洪水事件的较好示踪标志. 根据 ${ }^{210} \mathrm{~Pb}$ 堆积速率, 研究剖面的粒度及 TOC/TN 比值清晰地记录了长江干流 1850 1954 年期间的若千次特大洪水事件, 与历史文献和水文监测资料吻合. 然而自 20 世纪 60 年代以来, 长江流域人类活动显著增强, 尤其 是大量水坝兴建, 将大量粗颗粒泥沙和沉积有机质蓄积在水库中, 而显著改变长江下游干流的悬 浮沉积物粒度和有机质组成, 因而难以可靠地指示近 50 年来的洪水事件.
\end{abstract}

关键词

洪水事件

长江

沉积物

粒度参数 有机元素
长江作为中国第一大河，近百年来频频发生的 洪水灾害严重影响了社会经济发展和人民生活. 全 球变暖也导致中国降水的区域变化, 更易引发中国 大江大河流域发生洪水 ${ }^{[1]}$. 根据 1840 1992 年期间中 国七大江河水灾发生情况的统计，长江流域各等级 水灾总的发生次数居首位, 共计 76 次, 明显高于黄 河等流域 ${ }^{[2]}$. 古洪水研究一直受到各国学者关注, 如 对美国众多河流的古洪水水文研究可以追溯到 1938 年甚至更早 ${ }^{[3]}$. 而近十几年来, 古洪水重建更成为全 球变化研究的一个热点, 在中国也颇受重视. 国内一 些学者运用考古学、第四纪地质学等方法开展了长江 中上游流域和黄河流域的全新世古洪水研究, 得到 不少重要认识 ${ }^{[4-8]}$. 但迄今从沉积学与有机地球化学 结合的角度, 对长江下游近河口区高分辨率古洪水 沉积记录的研究几乎未开展, 本文通过对长江下游 主河道一个新生成沙洲的剖面沉积物的系统研究, 探讨沉积粒度和有机地球化学参数对洪水沉积的示 踪意义, 重建过去近 150 年来的现代洪水事件.

\section{1 剖面沉积特征与分析方法}

研究剖面(LGZ)位于江苏省扬中市西北角长江主 河道一个新生成的江心洲上, 地理坐标为 $32^{\circ} 18^{\prime} 23.6^{\prime \prime} \mathrm{N}$, $119^{\circ} 45^{\prime} 13.1^{\prime \prime} \mathrm{E}$, 标高为 $7.2 \mathrm{~m}$. 据扬中县志记载, 该 沙洲约在清朝同治年间(1862 1874 年)出露水面, 当 地原住民普遍反映该沙洲在 20 世纪解放前露出水面 的面积就很大了, 至今一直稳定生长. 目前, 该沙洲 面积大约 $8 \mathrm{~km}^{2}$, 无常住居民, 无工业活动, 人类活 动很弱, 基本保持了长江下游自然的沉积动力环境, 非常适合开展古沉积环境重建研究. 2008 年 3 月人工 开挖 LGZ 剖面长 $2.0 \mathrm{~m}$, 以 $1 \sim 2 \mathrm{~cm}$ 间隔采样, 共采集 101 个样品. 该剖面中夹有较多芦苇植物根系, 以顶部 $20 \mathrm{~cm}$ 居多. 沉积物主要为粉砂质黏土, 其中 $0 \sim 70 \mathrm{~cm}$ 为黄褐色土壤层, 75 112 cm 为褐红色铁锰淀积层, $124 \mathrm{~cm}$ 以下为橄榄灰色黏土层. 黏土层中夹杂若干 层厚度不等的粉砂层和极细砂层(图 1). 为测试该地区 的沉积速率, 选择 LGZ 剖面附近的一个 $1.49 \mathrm{~m}$ 长的 PVC 管状岩芯样品, 分别送南京大学和韩国 Chun- 
gnam 大学运用 $\alpha$ 和 $\gamma$ 谱仪进行 ${ }^{210} \mathrm{~Pb}$ 测试, 得到平均 堆积速率为 $0.97 \mathrm{~cm} / \mathrm{a}$. 考虑到 $\mathrm{PVC}$ 管取样过程中的 压缩, 我们对该孔的 ${ }^{210} \mathrm{~Pb}$ 沉积速率进行了校正. 研 究认为, 压缩率与含水量及分选性关系较大 ${ }^{[9]}$. 本孔 平均含水率为 $25 \%$, 分选系数 $S D$ 平均值为 1.75 . 依 据王爱军等人(2006)文章中推算的压缩率与含水量 及分选系数的关系, 计算得到本孔压缩率大约为 1.39, 校正采样压缩后的实际平均沉积速率约为 $1.34 \mathrm{~cm} / \mathrm{a}$.

在实验室内, 先用去离子水浸泡样品, 去除明显 的植物碎屑; 经 $1 \mathrm{~mol} / \mathrm{L}$ 优级纯盐酸和 $10 \% \mathrm{H}_{2} \mathrm{O}_{2}$ 去 除有机质和碳酸盐后, 在海洋地质国家重点实验室 用激光粒度分析仪(Coulter LS230)进行沉积粒度测定, 测试误差 $\leqslant \pm 1 \%$. 用浓度 $1 \mathrm{~mol} / \mathrm{L}$ 的优级纯盐酸处理 样品, 去除碳酸盐矿物, 再用去离子水反复清洗样品, 低温烘干, 研磨后供总有机碳(TOC)和总氮(TN)分析. 有机元素分析采用 EA1110 型有机元素分析仪 (Thermo 公司的 Carlo Erba), 以纯有机化合物 Crystine
和 Sulphanilamide 作为标样, 分析精度为 $0.5 \%$.

\section{LGZ 剖面沉积粒度与有机元素组成}

LGZ 剖面的沉积物粒度和有机元素组成见图 1. LGZ 剖面沉积物以粉砂质黏土和黏土质粉砂为主. 中值粒径 $M_{\mathrm{d}}$ 作为沉积物的主要粒度参数, 可指示沉 积物粒径频率分布的中心趋向, 反映颗粒搬运时的 平均动能. 该剖面中值粒径为 5.3 7.4 $\Phi$, 标准偏差 为 $1.5 ~ 2.0$, 总体分选性较差, 粒度变化较大. 粉砂平 均含量在 64\% 82\% 之间，黏土含量在 10\% 35\% 之间， 而砂含量多低于 5\%, 但剖面中存在几层明显的砂含量 峰值层, 最高达 $25 \%$ 左右. 该剖面的沉积物粒度从上 而下呈现明显两段式分布(图 1), 上段 0 70 cm 自上而 下粒度由粗到细变化, 砂含量几乎无变化, 而黏土向 下增多, 粉砂变少. 70 200 $\mathrm{cm}$ 的下段粒径变化幅度 大, 尤其是在 $73,93,103,120,155,95 \mathrm{~cm}$ 等处粒度突 变, 砂含量突增而黏土含量显著减小; 偏度和峰度也 变化显著(图 1).

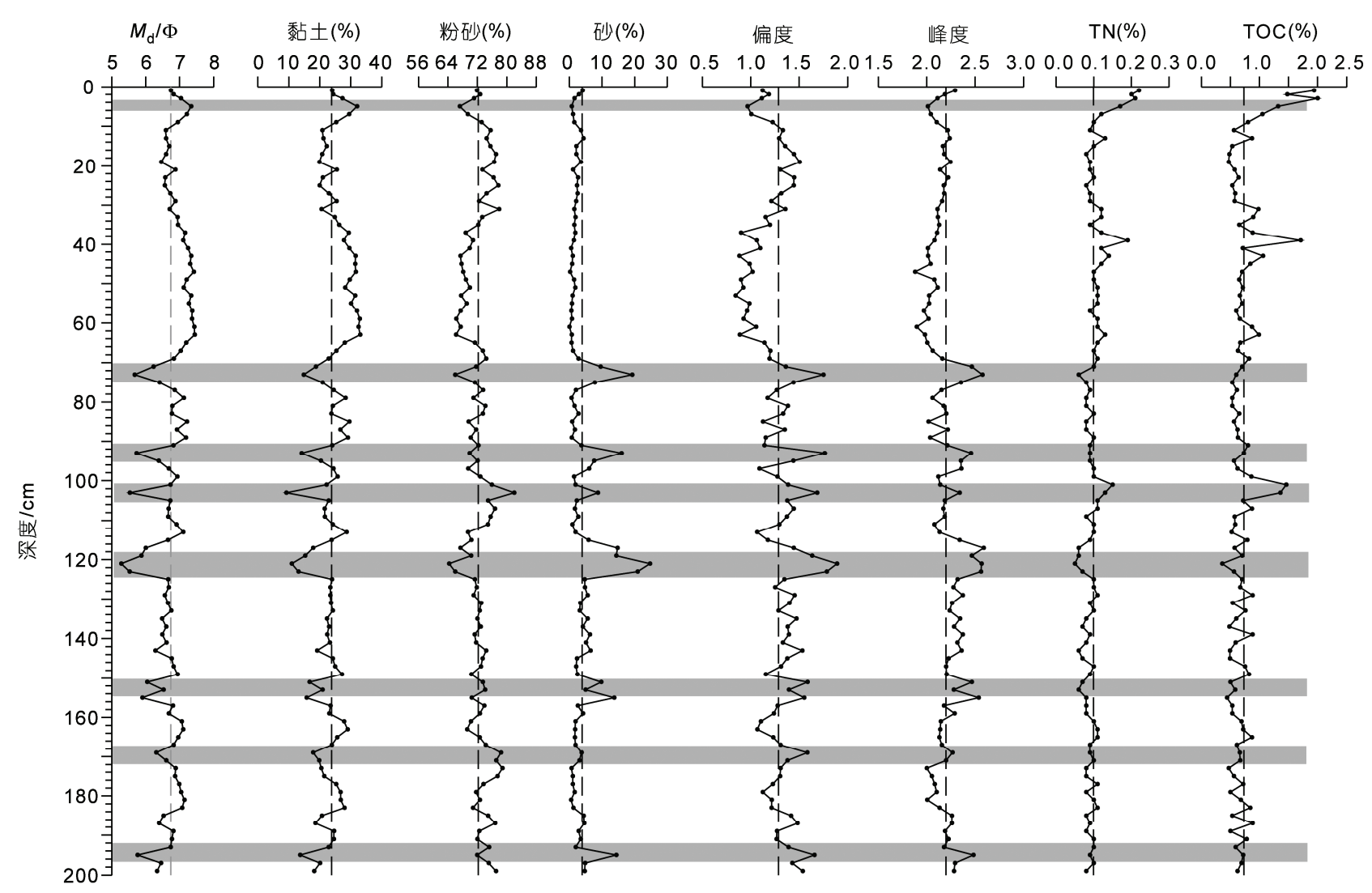

图 1 长江下游 $\mathbf{L G Z}$ 剖面沉积粒度与有机元素组成变化 
粒度概率累积曲线可综合反映粒度分布特征以 及颗粒搬运方式，而搬运方式与一定的沉积环境相 联系. 因此, 粒度概率累积曲线被广泛运用于沉积动 力过程及沉积环境的判别. LGZ 剖面沉积物的概率累 积曲线(图 2)显示, 几层砂质沉积物 $(73,119,155 \mathrm{~cm}$ ) 具有明显的四段或五段式累积曲线形态, 滚动组分 $(0 \sim 2 \Phi)$ 明显, 斜率较大, 分选性好, 指示水动力突然 增强. 其后跳跃组分存在冲刷-回流分界点(约 $3 \Phi$ ), 前后两段在分选和中值上略有差异, 反映水动力略 有变化. 悬移组分较平缓, 占 $50 \%$ 及以上. 而该剖面 其他深度的非砂质沉积物均表现为典型河流相沉积 的三段式曲线特征 ${ }^{[10]}$, 缺失滚动组分, 且以悬移组 分为主, 占 70\% 80\%以上.

由 Passega 提出的沉积物 $C-M$ 图也被广泛运用于 沉积环境的判别. $C$ 值是累积曲线上颗粒含量 $1 \%$ 处对 应的粒径, 代表水动力摚动开始搬运的最大能量; $M$ 值是累积曲线上 $50 \%$ 处对应的粒径, 即中值粒径, 代 表水动力的平均能量 ${ }^{[10]} . C-M$ 图既考虑了介质环境中 整体的沉积搬运机制与沉积作用, 也考虑了粗颗粒组 份的搬运形式, 因而在现代与古代沉积环境研究中得 到较广泛运用, 尤其适用于典型牵引流沉积环境的解 释. 在 $C-M$ 图中, $\mathrm{LGZ}$ 剖面的砂质沉积层与非砂质沉 积的分布范围明显不同, 后者分布集中且基本平行于 $C-M$ 线, 介于牵引流的均匀悬浮与静水悬浮沉积之间, 反映典型的较稳定河流漫滩沉积环境; 而砂质沉积物 的投点相对分散, 以均匀悬浮为主, 代表较强和混合 的水动力条件, 具有洪水沉积的普遍特征(图 3).

LGZ 剖面沉积物中 TOC 和 TN 含量总体变化不

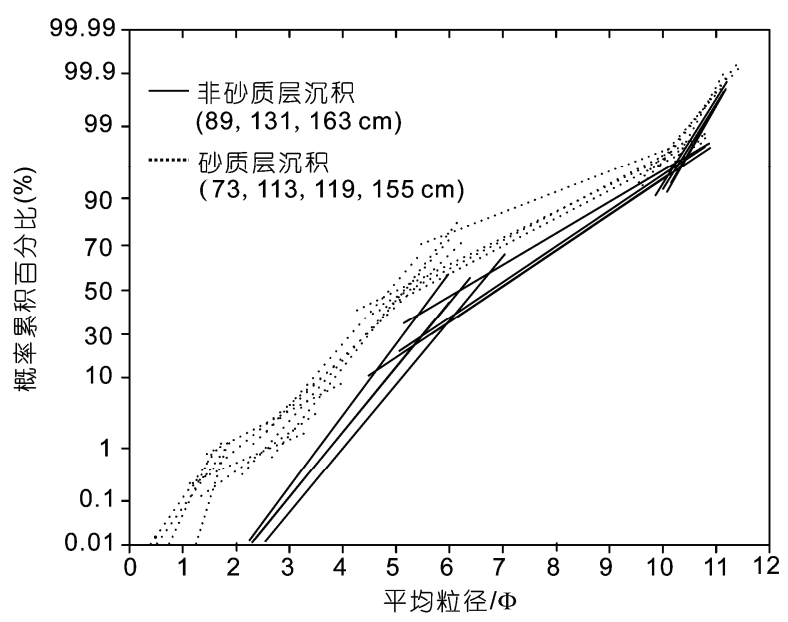

图 2 长江下游 LGZ 剖面沉积物的正态概率累积曲线

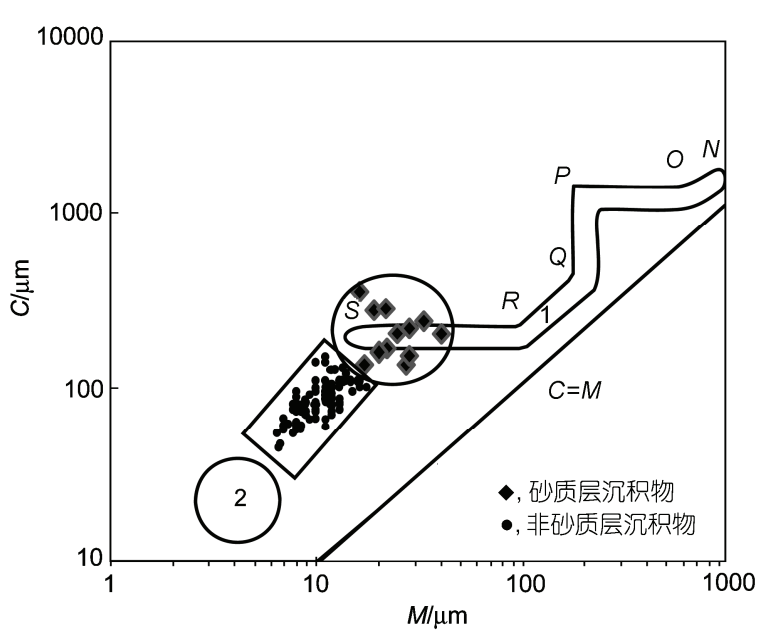

图 3 长江下游 LGZ 剖面样沉积物 $\boldsymbol{C}-\boldsymbol{M}$ 图

$N O$ 段为滚动; $O P$ 段为滚动 + 悬浮; $P Q$ 段为悬浮 + 滚动; $Q R$ 段为递变 悬浮; $R S$ 段为均匀悬浮. 1 , 牵引流沉积, 由 $N-S$ 段组成; 2 , 静水或远 洋悬浮沉积

大(图 1). TOC 含量为 $0.30 \%$ 2.34\%, 平均为 $0.74 \%$; $\mathrm{TN}$ 含量为 $0.04 \% \sim 0.23 \%$, 平均为 $0.10 \%$. LGZ 剖面沉 积物的 TOC 和 TN 含量基本落在现代长江水系沉积 物的有机元素组成范围内 ${ }^{[11]}$. TN 和 TOC 含量显著正 相关, 相关系数达 0.83 . 值得注意的是, $\mathrm{TN}$ 与 $\mathrm{TOC}$ 含量在剖面顶部 $10 \mathrm{~cm}$ 内显著增大, 呈现峰值, 推测 可能与近年来流域人类活动加剧, 释放到长江中的 有机污染物急剧增加有关; 但也可能是由于 $10 \mathrm{~cm}$ 以 上芦苇根系较多, 导致碳、氮含量较高. 植物根系的 分布直接影响到表土有机碳的垂直分布, 大量死根 腐解可提供丰富的有机碳 ${ }^{[12]}$; 另外, 大量的地表枯 枝落叶也是表层土壤有机碳的重要来源 ${ }^{[13]}$.

\section{3 粒度和有机元素组成对洪水事件沉积的 指示}

沉积物的粒度特征被广泛运用于现代和古代洪 水事件沉积的识别 ${ }^{[14,15]}$. 洪水漫滩初期水动力较强 且变化较大, 发生快速沉积, 粒度相对较粗, 分选较 差. 洪峰过后的洪水回流时期水动力条件相对较弱, 沉积相对缓慢, 粒度较细, 分选较好. 因此, 洪水沉 积在粒度上主要表现为粒度参数的峰值突变, 底部 突然粒度变粗, 然后多逐渐变细的旋回变化 ${ }^{[16]}$. LGZ 剖面沉积粒度主要参数在埋深 $70 \mathrm{~cm}$ 向下, 出现若干 层典型的中值粒径、黏土和砂含量、偏度等峰值, 且 每个粒度突变层主要表现为底部粒度突然增大, 向 
上逐渐变细的过程(图 1), 与洪水沉积的粒度特征非 常相似. LGZ 剖面的几层砂质沉积具有明显的四段或 五段式概率累积曲线, 较高的滚动组分指示突然增 强的水动力条件, 跳跃组分的冲刷-回流分界点在 $3 \Phi$ 左右, 与典型河流相沉积的三段式曲线特征明显不 同(图 2). 在 $C-M$ 图中, LGZ 剖面的砂质沉积层与非 砂质沉积的分布明显不同, 反映出较强且混合的水 动力条件(图 3). 因此, 我们推测长江下游 LGZ 剖面 中下部这几层粒度参数突变的砂质沉积层反映了水 动力沉积环境的突然变化, 清晰地指示洪水事件, 其 概率累积曲线与朱诚等人 ${ }^{[5]}$ 在长江中游的中坝遗址 地层的全新世古洪水沉积层非常接近.

沉积物中有机元素 $(T O C, T N)$ 组成主要受有机质 来源和降解速率、沉积粒度和矿物组成以及沉积后次 生变化等影响, 而 TOC/TN 比值更主要受沉积有机质 来源和降解程度控制 ${ }^{[17,18]}$. 一般认为, 沉积物中黏土 含量愈高, 有机质愈丰富. LGZ 剖面样品中, TOC 和 $\mathrm{TN}$ 含量与中值粒径 $M_{\mathrm{d}}$ 的总体相关性并不好, 相关系 数均在 0.1 以下, 反映出沉积有机质组成并不受沉积 粒度控制，而沉积有机质来源是更主要的控制因素.

新鲜水生澡类有机质的 $\mathrm{C} / \mathrm{N}$ 比多在 3 8 之间，而 来自于脉管类陆生高等植物有机质的 $\mathrm{C} / \mathrm{N}$ 比为 20 , 甚至更高. 但有机质在埋藏后迅速降解可显著降低 沉积有机质的 $\mathrm{C} / \mathrm{N}$ 比 ${ }^{[17]}$; 如现代长江水系沉积物的 有机质主要来自流域土壤 $\mathrm{C}_{3}$ 类型的高等植被 ${ }^{[1]}$, 但 其 $\mathrm{C} / \mathrm{N}$ 比多在 10 以下 ${ }^{[11,18]}$. LGZ 剖面的 $\mathrm{TOC} / \mathrm{TN}$ 比 值波动较大, 表层 0 10 cm 出现峰值, 而10 25 cm 处 出现最低值(图 4). TOC/TN 比值为 5.3 10.8, 平均为 7.3 , 与现代长江河漫滩沉积物中的 TOC/TN 比值接 近, 反映 LGZ 剖面沉积有机质主要来自长江中上游 流域的表土侵蚀，其 TOC/TN 比值基本继承了流域 表层土壤或风化沉积物中的有机质组成. 剖面中 $\mathrm{TOC} / \mathrm{TN}$ 最显著的变化是在剖面的中下部多次出现 明显的峰值, 在埋深 $120 \mathrm{~cm}$ 处, TOC/TN 比值最高, 达 10.8(图 4). LGZ 剖面中, $\mathrm{TOC} / \mathrm{TN}$ 与中值粒径 $M_{\mathrm{d}}$ 曲线在上部 $70 \mathrm{~cm}$ 内并无明显的相关性，但在 $70 \mathrm{~cm}$ 以下相关性显著，特别是在 $70 \sim 155 \mathrm{~cm}$ 段，若干 TOC/TN 峰值与中值粒径峰值明显对应, 即沉积粒度 突然变粗的层位, TOC/TN 比值也显著增大(图 4).

洪水期间，尤其是山洪爆发(flash flood)可以显 著增加地表侵蚀力, 将流域土壤和表土中大量腐殖 质或未降解完全的较新鲜有机碎屑直接带人河水中,
随悬浮颗粒物质一起向下游输运，随后沉积在河漫 滩上. 不少研究揭示, 砂质河流沉积物中富集有机碎 屑, 如植物根系等 ${ }^{[15,18,19]}$. 新鲜的有机残屑或未降解 完全的腐殖质中 $\mathrm{C} / \mathrm{N}$ 比要明显高于成熟土壤中降解 完全的有机质 ${ }^{[18-20]}$. 长江中上游由于海拔地势较高, 在夏季大洪水期间，除了可以搬运大量粗颗粒泥沙 进人下游外，也带来大陆流域表土中新鲜的有机残 屑或未降解完全的腐殖质，从而导致砂质沉积物中 $\mathrm{TOC} / \mathrm{TN}$ 比显著升高. $\mathrm{Wu}$ 等人 ${ }^{[11]}$ 的研究也揭示长江 中上游干流悬浮物的颗粒有机碳含量较高, 反映出 流域土壤有机质的贡献. 因此, LGZ 剖面中下部的 $\mathrm{TOC} / \mathrm{TN}$ 比值与沉积粒度参数之间具有较好的相关 变化(图 4), 二者均可指示现代洪水事件沉积.

\section{4 近 150 年来长江下游现代洪水事件的重建}

施雅风等人根据历史文献资料系统整理了长江 流域 1840 1999 年的大洪水记录 ${ }^{[21]}$, LGZ 剖面根据 ${ }^{210} \mathrm{~Pb}$ 实测并经压缩校正的平均堆积速率为 $1.34 \mathrm{~cm} / \mathrm{a}$, 刚好代表了近 150 年来的长江下游干流沉积. 该剖面 沉积物的粒度参数和沉积有机质的 TOC/TN 比值清 晰地揭示出近 150 年来, 长江下游存在几次显著的洪 水事件. LGZ 剖面埋深 73 和 $103 \mathrm{~cm}$ 处粒度参数(中值 粒径 $M_{\mathrm{d}}$ )与 TOC/TN 比值呈峰值, 其堆积年代分别约

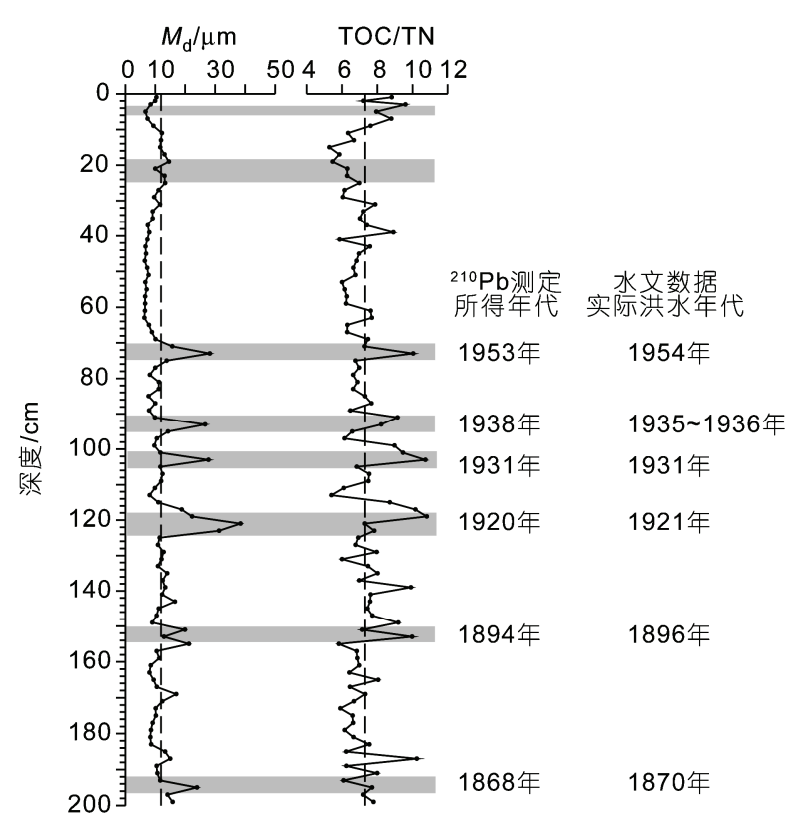

图 $4 \mathrm{LGZ}$ 剖面沉积有机质的 TOC/TN 比值与中值粒径 $\left(M_{\mathrm{d}}\right)$ 指示若干次洪水事件 
为 1953 和 1931 年, 推测分别对应于 1954 和 1931 年 长江流域的特大洪水. 而依次推算, 钻孔其他几层粒 度和 TOC/TN 比突变的沉积层, 如 92, 118, 153 和 187 $\mathrm{cm}$ 处的沉积年龄分别约为 1938, 1920, 1894 和 1868 年(图 4), 很好地对应于历史文献记录的长江流域 1935 1936, 1921, 1896 和 1870 年几次大洪水事件 ${ }^{[21]}$. 个别洪水事件的剖面沉积年龄与历史数据相差约 2 3 a, 可能同 ${ }^{210} \mathrm{~Pb}$ 年龄测试的误差有关, 也与河流 沉积环境的不稳定性有关. 显然, 这也反映了自然地 理状况下沉积动力环境的复杂性.

为验证 ${ }^{210} \mathrm{~Pb}$ 实测的剖面平均堆积速率 $1.34 \mathrm{~cm} / \mathrm{a}$ 是否可靠, 我们反过来假设剖面中下部沉积粒度与 TOC/TN 比值峰值层位都代表了长江流域主要的洪 水事件, 且 1954 年长江全流域大洪水对应 $73 \mathrm{~cm}$ 处 峰值, 以到 2007 年剖面顶部沉积为上界, 计算得 LGZ 剖面的平均沉积速率约为 $1.37 \mathrm{~cm} / \mathrm{a}$; 同理依次 类推, 假设 $103 \mathrm{~cm}$ 处峰值对应 1931 年特大洪水, 得 沉积速率为 $1.36 \mathrm{~cm} / \mathrm{a}$; 底部 $187 \mathrm{~cm}$ 处峰值对应 1870 年大洪水, 得到沉积速率为 $1.36 \mathrm{~cm} / \mathrm{a}$. 考虑河漫滩 沉积环境的不稳定性以及洪水期间的快速沉积, 我 们依据近 150 年来主要洪水事件推测的剖面平均沉 积速率(约 $1.36 \mathrm{~cm} / \mathrm{a}$ )与 ${ }^{210} \mathrm{~Pb}$ 实测值(约 $1.34 \mathrm{~cm} / \mathrm{a}$ )还 是相当接近的, 这也证明根据剖面粒度和有机元素 组成所揭示的 1850 年以来长江流域几次大洪水事件 是可靠的. 目前, ${ }^{210} \mathrm{~Pb}$ 测年方法在河漫滩(边滩、心滩) 沉积环境中运用较少, 国内外河流沉积学研究中也 鲜见河漫滩沉积速率的研究报道. 本文作为一种尝 试, 选择的 LGZ 剖面位于扬中长江干流主河道的一 个稳定沙洲的尾部位置, 是沙洲生长较快和最稳定 的地方, 其沉积动力环境相对上游洲头和主河道两 侧要弱, 即使在洪水期间较强的水动力环境也难以 造成明显的侵蚀, 因此该剖面的平均沉积速率相对 稳定. 过去 100 多年来, 自从该沙洲出露水面后, 研 究剖面点即洲尾的沉积地层主要反映的是长江主流 水位的变化, 而不是干流河岸侧向迁移或河漫滩冲 刷与堆积的结果. 因此, 该剖面是长江下游近河口地 区一个非常理想的古洪水研究地点.

值得注意的是 LGZ 剖面 $70 \mathrm{~cm}$ 向下粒度参数如 $M_{\mathrm{d}}$ 与 $\mathrm{TOC} / \mathrm{TN}$ 峰值可以一一对应, 而在上部 $70 \mathrm{~cm}$ 内又不存在明显的对应关系(图 1,4). 据水文实测资 料, 1954 1990 年期间长江流域还有 9 次较大洪水 ${ }^{[21]}$, 即 LGZ 剖面 $70 \mathrm{~cm}$ 向上应该有 9 次可能对应的粒度
与有机元素变化峰值, 但在实测数据中并没有反映 (图 1,4). 特别是 1998 年全流域特大洪水, 以沉积速 率 $1.34 \mathrm{~cm} / \mathrm{a}$ 来计算, 对应深度约为 $12 \sim 13 \mathrm{~cm}$, TOC/ $\mathrm{TN}$ 和中值粒径都没有显著增大. 在 2008 年 3 月雷公 嘴江心洲野外考察采样时, 我们用 GPSmap 60CSx 测 得采样点的标高为 $7.2 \mathrm{~m}$. 据当地水文资料记载, 1991 年大洪水时, 7 月 14 日扬中长江水位高达 $7.53 \mathrm{~m}$, 而 1998 年 8 月 1 日更突破历史最高水位, 达到 $8.04 \mathrm{~m}$. 研究剖面点肯定被淹. 因此, 长江流域近 50 年来的 特大洪水肯定会在该研究剖面留下沉积记录.

上部 $70 \mathrm{~cm}$ 沉积物的粒度和 TOC/TN 比值与洪水 事件对应较差, 我们推测可能有两个原因, 一是 $70 \mathrm{~cm}$ 向上的沉积物中芦苇根系特别发育, 沉积物的粒度 和有机元素组成受原地生物扰动影响, 而难以准确 反映长江洪水期间由中上游携带下来的粒度与有机 质组成. 另一个更可能的原因是 20 世纪 50 60 年代 以来(相当于沉积深度 $70 \mathrm{~cm}$ 左右), 长江流域人类活 动特别显著 ${ }^{[22,23]}$, 长江搬运人海的悬浮沉积物和颗 粒有机质来源与组成已经不同于 $50 \mathrm{a}$ 前的自然状态. 大通站水沙年际变化反映出, 1953 年以来长江径流 量变化不大, 但输沙量和含沙量持续降低 ${ }^{[24]}$. 尤其 是长江流域自 20 世纪 60 年代以来大量大坝建设, 可 以显著地将一些粗颗粒泥沙蓄积在水库中, 进而改 变洪水期间从中上游携带到下游近河口区的悬浮物 粒度与有机质组成. 以三峡水库为例, 三峡大坝蓄水 后(2003 2005), 长江干流主要水文控制站(寸滩、宜 昌、汉口和大通站)的年均悬沙中值粒径明显小于多 年平均值以及蓄水前一年(2002)实测值, 反映三峡水 库蓄水引起大量泥沙特别是粗颗粒泥沙在库区落淤, 从三峡大坝下泻的非正常清水导致宜昌站至沙市站 之间的长江河道遭受到严重冲刷, 从该段河道冲刷 起来的粗颗粒泥沙随着变小的河道坡降和河水流速, 又逐渐沉降在沙市和汉口之间的河道, 而使得下游 干流悬浮泥沙粒径明显降低 ${ }^{[25]}$. 因此, 由于近几十 年的大坝建设, 在长江下游干流难以再通过沉积粒 度参数与有机元素组成来可靠反映长江近 50 年来的 大洪水事件.

\section{5 结论}

长江下游干流一个江心洲剖面的沉积物主要为 粉砂质黏土和黏土质粉砂, 分选总体较差. 上部 $70 \mathrm{~cm}$ 沉积粒度向下先变粗再变细. 而 $70 \mathrm{~cm}$ 以下出现若干 
粒度参数突变层, 中值粒径和砂含量显著增大, 偏度 和峰度也明显变化. 粒度概率累积曲线和 $C-M$ 图清 晰揭示出非砂质沉积层反映正常的河流悬浮沉积环 境, 而几层砂质沉积具有明显的四段或五段式概率 累积曲线, 较高的滚动组分指示突然增强的水动力 条件, 为洪水事件沉积, 其粒度参数特征与长江中游 地区的洪水沉积粒度组成基本一致.

剖面样中有机元素组成基本落在现代长江悬浮 物和河漫滩沉积有机质组成范围内, 反映长江中上 游搬运来的物质是剖面沉积有机质的主要来源. $\mathrm{TOC} / \mathrm{TN}$ 比值与中值粒径在剖面 $70 \mathrm{~cm}$ 深度以下具有 非常好的相关性，其峰值基本上可以一一对应，也可
以作为洪水事件沉积的指示标志. 大洪水期间，流域 表土侵蚀冲刷强烈, 可以将大量粗泥沙颗粒和未降 解的有机碎屑带人下游地区, 从而导致较粗的沉积 粒度和较高的 $\mathrm{TOC} / \mathrm{TN}$ 比值. 根据 ${ }^{210} \mathrm{~Pb}$ 实测的堆积 速率, 研究剖面的粒度与有机元素组成清晰地记录 了长江干流 1850 1954 年期间的若干次大洪水事件, 与历史文献和水文监测资料相当吻合. 然而自 20 世 纪 60 年代以来, 由于长江流域人类活动显著增强, 干支流大小型水坝大量兴建, 长江人海输沙量与含 沙量持续降低, 进人下游的沉积物粒度和有机元素 组成也发生明显变化, 不同于之前的自然状态，因而 难以可靠地指示近 50 年来的洪水事件.

\section{参考文献}

1 姜剘, 施雅风. 全球变暖、长江水灾与可能损失. 地球科学进展, 2003, 18: 277-284

2 张强, 杨达源, 施雅风, 等. 川江中坝遗址 5000 年来洪水事件研究. 地理科学, 2004, 24: 715一720

3 Baker V R. Paleoflood hydrology: Origin, progress, prospects. Geomorphology, 2008, 101: 1-13

4 杨达源, 谢悦波. 古洪水平流沉积. 沉积学报, 1997, 15: 29-32

5 朱诚, 郑朝贵, 马春梅, 等. 长江三峡库区中坝遗址地层古洪水沉积判别研究. 科学通报, 2005, 50: 2240-2250

6 朱诚, 马春梅, 王慧麟, 等. 长江三峡库区玉溪遗址 T0403 探方古洪水沉积特征研究. 科学通报, 2008, 53(增刊 I ): 1-16

7 葛兆帅, 杨达源, 李徐生, 等. 晚更新世晚期以来的长江上游古洪水记录. 第四纪研究, 2004, 24: 555一 560

8 王长燕，赵景波，郁耀间. 黄河兰州段高河漫滩洪水沉积及其气候意义. 海洋地质与第四纪地质, 2008, 28: 125一132

9 王爱军, 高抒, 贾建军. 江苏王港潮间带柱状样的压缩和校正. 沉积学报, 2006, 24: 555-561

10 赵澄林, 朱筊敏. 沉积岩石学. 北京: 石油工业出版社, 2001. 57-71

11 Wu Y, Zhang J, Liu S M, et al. Sources and distribution of carbon within the Yangtze River system. Estuar Coast Shelf S, 2007, 71: 1325

12 Jobbagy E G, Jackson R B. The vertical distribution of soil organic carbon and it's relation to climate and vegetation. Ecol Appl, 2000, 10: $423-436$

13 Fang X, Tian D L, Xiang W H, et al. Vertical distribution of soil organic carbon in Cunninghamia lanceolata plantation. J Zhejiang Forest Coll, 2004, 21: 418-423

14 Baker V R, Webb R H, House P K. The Scientific and Societal Value of Paleoflood Hydrology. In: House P K, ed. Ancient Floods, Modern Hazards: Principles and Applications of Paleoflood Hydrology. Washington DC: the American Geophysical Union, 2002. 1-19

15 Brown S L, Bierman P R, Andrea L, et al. 10000 yr record of extreme hydrologic events. Geology, 2000, 28: 335-338

16 谢远云, 李长安, 王秋良, 等. 江汉平原近 3000 年来古洪水事件的沉积记录. 地理科学, 2007, 27: 81-84

17 Meyers P A. Organic geochemical proxies of paleoceanographic, paleolimnologic, and paleoclimatic processes. Org Geochem, 1997, 27: $213-250$

18 唐珢, 杨守业, 李保华, 等. 长江三角洲冰后期沉积物的有机碳氮和有机碳同位素组成与古环境指示. 海洋地质与第四纪地质, 2006, 26: $1-10$

19 Sirocko F, Dietrich S, Pfahl S, et al. Flash floods of the last 1000 years in central Europe documented by laminated freeze cores from Eifel maar lakes. Geophys Res Abs, 2008, 10: EGU2008-A-03185 Meyers P A. Preservation of elemental and isotopic source identification of sedimentary organic matter. Chem Geol, 1994, 144: 289-302 施雅风，姜粀，苏布达. 1840 年以来长江大洪水演变与气候变化关系初探. 湖泊科学, 2004, 16: 289-297

22 Gao S. The Three Gorges Dam: Development and environmental issues. Macalester Int, 2007, 18: 146-171

23 李从先, 杨守业, 范代读, 等. 三峡大坝建成后长江输沙量的减少及其对长江三角洲的影响. 第四纪研究, 2004, 24: 495- 500

场作升，陈晓辉．百年来长江口泥质区高分辨率沉积粒度变化及影响因素探讨. 第四纪研究, 2007, 27: 690一699

褚忠信，翟世奎，章否，等. 三峡水库 2003 年蓄水对长江悬沙中值粒径的影响. 海洋湖泊通报, 2007, 3: 23-28 